\title{
Consideraciones acerca de los actores criminales de Colombia, como mutaciones del conflicto interno, desde la perspectiva económica y de la historia de las relaciones internacionales (2006-2018)*
}

Patricio García Pérez

Profesor adjunto en el Departamento de Historia de la Universidad de Santiago de Chile. Correo electrónico: garcpatricio@gmail.com. El autor es doctor en Historia por la Universidad de Santiago de Chile. Es miembro permanente del Seminario Internacional sobre Historia de la Violencia en América Latina. Entre sus publicaciones recientes tenemos: "Organizaciones armadas post AUC, Del pasado contrainsurgente al presente de criminalidad transnacional, 2006-2016”, Revista Izquierdas No. 49 (2020) y "Las Autodefensas Unidas de Colombia, AUC, (1994-2005) Historia de un actor de origen estatal antisubversivo y de alcance transnacional en el Conflicto interno" (Chile: LOM, 2019). Entre sus temas de interés están los conflictos armados post guerra fría, en especial en la historia de los actores no estatales del conflicto armado colombiano, el paramilitarismo, las Autodefensas Unidas de Colombia y las organizaciones criminales transnacionales.

Julián Andrés García SanHueza

Ayudante de investigación Centro de Estudios del Conflicto y Cohesión Social del Departamento de Economía de la Universidad de Chile. Correo electrónico: jgarcias@fen.uchile.cl. El autor es Ingeniero Comercial y magíster en Economía de la Facultad de Economía y Negocios de la Universidad de Chile.

Recibido: 17 de enero de 2020

Aprobado: 8 de mayo de 2020

Modificado: 9 de mayo de 2020

Artículo de investigación científica

DOI: https://doi.org/10.15648/hc.39.2021.2963

Este artículo forma parte del proyecto "Actores criminales de Colombia, como mutaciones del conflicto interno, desde la perspectiva económica y de la historia de las relaciones internacionales (20062018)" financiación propia.

Esta publicación está bajo una licencia Creative Commons Reconocimiento-NoComercial 4.0 (c) BY-NC 
Consideraciones acerca de los actores criminales de Colombia, como mutaciones del conflicto interno, desde la perspectiva económica y de la historia de las relaciones internacionales (2006-2018)

\section{Resumen}

Esta investigación indaga en los actores armados del posconflicto de Colombia a partir de la desmovilización parcial de las Autodefensas Unidas de Colombia (AUC), el año 2006 y hasta la firma de los acuerdos de paz con las Fuerzas Armadas Revolucionaria de Colombia-Ejército del Pueblo (FARC-EP). Busca establecer la transformación de actores armados insurgentes y contrainsurgentes en delincuenciales transnacionales que impulsan un capitalismo de tipo criminal aprovechando los vacíos institucionales, la ausencia de actores económicos modernos e impactan el crecimiento económico y potencialidades de desarrollo en los departamentos del país en que se concentran. Se busca establecer un marco inicial para estudiar el impacto de los vacíos institucionales, economías ilegales y presencia de actores armados en el crecimiento económico de los departamentos de Colombia más golpeados por la violencia.

Palabras clave: Criminalidad transnacional, posconflicto, factores de riesgo institucional, capitalismo criminal, crecimiento económico.

Considerations about criminal actors in Colombia, as mutations of the internal conflict, from the economic perspective and the history of international relations (2006-2018)

\section{Abstract}

This study analyses the armed actors in Colombia's post-conflict from the partial demobilization of the United Self-Defenses Forces of Colombia (AUC in Spanish) in 2006 until the peace agreements signing with the Revolutionary Armed-Forces of Colombia-People's Army (FARC-EP). It aims at establishing the insurgent and counterinsurgent armed actors' transformation into transnational criminal groups promoting criminal capitalism, taking advantage of institutional gaps and the absence of modern economic actors, thus impacting economic growth and potential development in the country's departments where they are concentrated. This paper works towards an initial framework to study the impact of institutional gaps, illegal economies and the presence of armed actors on economic growth in the Colombian departments most affected by violence.

Key words: Transnational crime, post-conflict, institutional risk factors, criminal capitalism, economic growth. 
Considerações sobre os atores penal da Colômbia, como mutações do conflito interno, da perspectiva econômica e da história das relações internacionais (2006-2018)

\section{Resumo}

A presente pesquisa analisa os atores armados do pós-conflito da Colômbia desde a desmobilização parcial das Forças Unidas de Autodefesa de Colombia (AUC) em 2006 e até a assinatura dos acordos de paz com as Forças Armadas Revolucionárias do Colombia-Exército Popular (FARC-EP). Ele visa estabelecer a transformação de atores insurgentes e contra-insurgentes armados em criminosos transnacionais que dirigem um capitalismo criminoso aproveitando as lacunas institucionais, a ausência de atores econômicos modernos e impact antes nos potenciais de crescimento e desenvolvimento econômico nos departamentos do país em que se concentram. Ele busca estabelecer uma estrutura inicial para estudar o impacto de lacunas institucionais, economias ilegais e a presença de atores armados no crescimento econômico dos departamentos da Colômbia mais afetados pela violência.

Palavras-chave: Crime transnacional, pós-conflito, fatores de risco institucionais, capitalista criminal, crescimento econômico.

Considérations sur les acteurs pénaux de la Colombie, comme mutations du conflit interne, du point de vue économique et de l'histoire des relations internationales (2006-2018)

\section{Résumé}

La présente recherche passe en revue les acteurs armés du post-conflit colombien depuis la démobilisation partielle des Forces d'autodéfense unies de Colomia (AUC) en 2006 et jusqu’à la signature des accords de paix avec les Forces Armées Revolutionnaires de Colombienne-L'Armee Populaire (FARC-EP). Il vise à établir la transformation des acteurs insurgés et contre-insurgés armés en criminels transnationaux qui conduisent un capitalisme criminel tirant parti des lacunes institutionnelles, de l'absence d'acteurs économiques modernes et impactants dans la croissance économique et les potentiels de développement dans les départements du pays dans lesquels se concentrer. Il vise à établir un cadre initial pour étudier limpact des lacunes institutionnelles, des économies illégales et de la présence dracteurs armés dans la croissance économique des départements colombiens les plus touchés par la violence.

Mots clés: Criminalité transnationale, post-conflit, facteurs de risque institutionnels, capitalisme criminel, croissance économique. 


\section{INTRODUCCIÓN}

La investigación tiene como escenario histórico el conflicto colombiano, caracterizado por su extensión, heterogeneidad, intensidad variable, diversidades en el repertorio de la violencia y desde los años 90 , agudizado y protagonizado sobre todo por el paramilitarismo (fuerzas paraestatales), las guerrillas (contraestatales), el narcotráfico, y las fuerzas del Estado ${ }^{1}$. Disciplinariamente, se ubica en el campo de la Historia Económica y de las Relaciones Internacionales. La temporalidad considerada es la del 2006-2017, que corresponde a la desmovilización de las AUC, y hasta la firma del Acuerdo de paz con las FARC-EP.

Se concentra en las organizaciones armadas que actúan en ese período, predominantemente las de pasado paramilitar y que califican como actores delincuenciales transnacionales ${ }^{2}$, desarrollando acciones de control territorial y de la población que impactan negativamente el crecimiento económico nacional y regional, limitando las posibilidades de desarrollo. Al mismo tiempo promueven acciones de captura del Estado, de corrupción, y depredan rentas públicas. Un objetivo fundamental es presentar un estudio preliminar para investigar el impacto de la violencia de estas organizaciones luego de los procesos de desmovilización, sobre el crecimiento económico en 6 de los departamentos más golpeados por la violencia de grupos armados residuales.

Buscamos aportar evidencia respecto de que las diferencias en el crecimiento económico a nivel departamental podrían explicarse por elementos que denominaremos factores de riesgo. Estos afectan negativamente el crecimiento económico. La evidencia entregada en este trabajo busca incentivar posteriores investigaciones y contribuir a depurar el análisis de las políticas institucionales para enfrentar el posconflicto. Estudiamos esta relación a través de 3 metodologías: test de medias, análisis gráfico y análisis de correlaciones usando variables proxies de los factores, el Producto Interno Bruto y usando un

1 Carlos Medina Gallego y Mireya Tellez Ardila, La violencia parainstitucional, paramilitar y parapolicial en Colombia (Rodríguez Quito Editores, 1994).

2 Juan Carlos Pereira Castañares, Historia de las relaciones internacionales contemporáneas (Barcelona: Ariel, 2009). 
horizonte temporal entre 2006-2016. Una mirada global a la economía colombiana provee $\mathrm{m}$ datos relevantes para concluir que las zonas de mayor crecimiento económico departamental, expresado como el PIB, son aquellas donde hay mayor modernización, extensión democrática, presencia del estado, transportes, comercio, salud, y educación. Es el caso de Bogotá, Antioquía, y Valle del Cauca donde se ubican la ciudad capital, Medellín, y Calí3.

Nuestra hipótesis, afirma que en el extenso conflicto armado Colombiano, las fragilidades y fallas institucionales ${ }^{4}$, los incumplimientos a los acuerdos de paz, unidos al incremento de las economías ilegales, la ausencia del Estado y de actores empresariales modernos en "espacios ingobernados" producen "factores de riesgo" y potencian el fortalecimiento, fragmentación y lucha por el control de materias primas ilegales, por organizaciones armadas de todo tipo, predominantemente criminales $^{5}$, carentes de motivaciones políticas, que protagonizan el período 2005-2016, produciendo efectos negativos en el crecimiento económico regional y nacional del país, al mismo tiempo que debilitan la democracia e impiden la paz .

La metodología es cualitativa y cuantitativa. Se realizó la revisión de bibliografía académica sobre el conflicto de Colombia. En segundo lugar, se realizó el análisis del comportamiento de las series recopiladas entre 2005-2017 que nos permite diagnosticar los departamentos de Colombia, que presentan una alta intensidad del conflicto armado, de economías ilegales y debilidades institucionales con respecto al resto de los departamentos. Se revisaron también series de datos estadís-

3 Estos departamentos presentaron el año 2018, de acuerdo al Departamento Administrativo Nacional de Estadística DANE, PIB mayores que el de Colombia (2,7\%). Otros como el Chocó $(-5,7 \%)$ considerado en este trabajo, son los más pobres y con mayor presencia de la violencia.

4 En ningún caso consideramos a Colombia como una forma de "estado fallido". Se trata de un Estado reconocido internacionalmente, que firma tratados de libre comercio, parte de la comunidad internacional, con poderes del estado elegidos por la población, aunque históricamente ausente en espacios de frontera donde la violencia germinó. Sobre el tema se puede revisar James Robinson, "La Miseria en Colombia", Desarrollo social No. 7 (2016).

5 Mary Kaldor, New and old wars: Organised violence in a global era (John Wiley \& Sons, 2013).

6 Fenómenos semejantes han sido analizados para condiciones de posconflicto en África (El Congo) y en el trabajo de Mary Kaldor para los Balcanes. 
ticos para el período 2000-2018, emitidos por el Estado como Forensis, Instituto Nacional de Medicina Legal sobre mortalidad nacional y homicidios, Informes de ingresos nacionales de la Dirección de Impuestos y Aduanas Nacionales (DIAN), los demográficos y estadísticas vitales del Departamento Administrativo Nacional de Estadísticas (DANE), de inversión extranjera del Ministerio de Industria Turismo y Comercio (MINCIT), los informes de inversión IAB Colombia, el Informe de auditoría de políticas públicas, oferta de narcóticos ilícitos del Observatorio de Drogas de Colombia (ODC), datos de cobertura educativa del Ministerio de Educación, Finanzas Públicas de la DNP, UPME Colombia y DANE para cobertura electrificado y acueducto y DANE para Secuestros.

El trabajo se encuentra dividido en los siguientes tópicos. En primer lugar, se expone el Marco teórico o revisión del estado del debate académico respecto de los conceptos que usaremos y de diagnóstico del problema a desarrollar. En segundo lugar, se presenta el proceso de desmovilización institucionalizados de las AUC (con mayor énfasis) y las FARC-EP en tanto principales actores del conflicto interno y bases sociales de las principales entidades criminales del posconflicto. En tercer lugar, se expone el carácter criminal transnacional y las bases económicas de las entidades armadas. Se culmina con la revisión a través de las metodologías señaladas de los impactos económicos de estas entidades en los departamentos de mayor conflictividad estudiando su explicación a través de los factores de riesgo descritos.

Se exponen a continuación los principales conceptos utilizados en la investigación y el modo intelectual en que son aplicados, procurando que es trabajo sea comprensible también a quienes no son expertos en la temática abordada.

En primer lugar, consideramos el concepto de "actores criminales transnacionales". Este, lo consideramos como el resultado de los debates teóricos en las relaciones internacionales durante la segunda mitad del siglo XX, entre las corrientes transnacionalistas y el neorrealismo. Tal como explica Esther Barbé (1995), este concepto permitirá dar cuenta de la noción de actor internacional como aquel que corresponde a 
unidades del sistema internacional (entidad, grupo, individuo) y que posee la habilidad para movilizar recursos y alcanzar sus objetivos. Así mismo, buscan ejercer influencia sobre otros actores del sistema y gozar de cierta autonomía. Esta definición, permitió plantear la existencia de actores que reemplazan soberanía por autonomía, como lo refiere García Segura desde inicios de la década del setenta.

Nuestra base teórica en ese campo, es el transnacionalismo que cuestiona el sistema de estados como estructura base del sistema internacional, reconociendo la existencia de una pluralidad de actores como lo señalan Robert Keohane y Joseph Nye (2005), en su texto "Transnational relations and world politics", dando un giro al paradigma tradicional estadocéntrico. ${ }^{7}$ Así mismo, plantean la necesidad de considerar interacciones a diversos niveles: transnacionales, interestatales y transgubernamentales, y enfatizan la capacidad o habilidad de los actores para discutir el concepto tradicional de soberanía. Por otro lado, Del Arenal $(2007)^{8}$ plantea los cambios que genera la consideración de actores no estatales al momento de estudiar la sociedad internacional, sus estructuras, dinámicas e interacciones. Estas plantean que, no se pueden comprender a ésta, sin considerar la acción de grupos empresariales, empresas transnacionales, Organizaciones No Gubernamentales (ONGs), grupos sociales de muy distinto alcance y naturaleza que actúan a nivel internacional. Tales como cárteles del narcotráfico, y mafias, por ejemplo.

En el mismo sentido se expresa el historiador Juan Carlos Pereyra (2009) 9 . Todos estos nuevos actores ponen en juego las formas tradicionales de ejercer poder (anteriormente concentrado de forma monopólica en los Estados) y llevaron a la elaboración de tesis como las de Susan Strange $e^{10}$ respecto al "poder estructural" o la idea del "poder blando" planteada

\footnotetext{
7 Robert Owen Keohane y Joseph S. Nye, Transnational relations and world politics (Cambridge, Mass.: Harvard University Press, 1971).

8 Celestino Del Arenal, Robert J. Art, y Robert Jervis, Introducción a las relaciones internacionales (Cali: Tecnos, 1984).

9 Juan Carlos Pereyra, "Historia de las relaciones internacionales".

10 Susan Strange, La retirada del Estado: la difusión del poder en la economía mundial, vol. 2 (Barcelona: Intermón Oxfam Editorial, 2001).
} 
por Joseph $\mathrm{Nye}^{11}$. Unimos a estas consideraciones una actualización y adecuación del concepto de "Fuerzas profundas" propuesto por los historiadores Renouvin y Durouselle ${ }^{12}$, iniciadores de la Historia de las Relaciones Internacionales ${ }^{13}$.

La criminalidad organizada, es aquella que busca "Establecer el control de toda la estructura económica de la ilegalidad mediante el ejercicio de la violencia y a través de estructuras organizadas en forma de empresas de propiedad privada legal"14. Además, actúa como "mafias armadas" en el sentido de Diego Gambetta, es decir ofrece seguridad privada, y se apropian de las rentas de los mercados legales e ilegales ${ }^{15}$. Según la Organización de Naciones Unidas (ONU) y la convención contra la delincuencia se puede denominar crimen organizado a las "actividades que concentran entre 3 o más personas para cometer crímenes en un tiempo prolongado para obtener beneficios económicos"16. En el marco de la globalización, las estructuras paramilitares, de pasado insurgente y sus continuadoras, pueden ser caracterizados como "un grupo de delincuentes que aúna fuerzas para llevar a cabo un delito específico, es similar a una empresa en la que todos desempeñan simplemente su parte de manera organizada" 17 , que han mejorado la eficiencia de sus actividades delictivas a través de estructuras delictivas transnacionales, pues la globalización ha facilitado el intercambio de bienes ilícitos, "y la consolidación de alianzas entre organizaciones criminales de todo el mundo"18. La adecuación de "mafia" a la realidad histórica colombiana que se utilizará es elaborada por el Information Technology Assets

11 Joseph S. Nye Jr, Soft power: The means to success in world politics (New York: Public affairs, 2004).

12 Pierre Renouvin et al., Historia de las relaciones internacionales (Madrid: Aguilar, 1969).

13 Pierre Renouvin et al., Historia de las relaciones internacionales.

14 María Ruiz Diaz, John Galeano Raquejo, y Edwin Oswaldo Gil Mateus, "Posconflicto colombiano y sus efectos económicos”, Revista CIFE: Lecturas de Economía Social 17 No. 27 (2015): 2.

15 Carlos Medina, Mafia, narcotráfico y bandas criminales en Colombia: elementos para un estudio comparado con el caso de México (Bogotá: Universidad Nacional de Colombia, 2012).

16016 Organización de Naciones Unidas (ONU, 2000).

17 Diego Gambetta, La mafia siciliana: el negocio de la protección privada (México: Fondo de cultura económica, 2007).

18 Jorge Enrique Linares Hamann, "Redes criminales transnacionales: principal amenaza para la seguridad internacional en la posguerra fría", Revista Criminalidad Vol. 50 No. 1 (2008): 371-384. 
Disposition (ITAD) del siglo XX, y construida por el historiador Carlos Medina Gallego (2012). Para éste, "La mafia en Colombia apunta a direcciones de acumulación y poder, recurre a la violencia ilegal y legal como mecanismo coercitivo y de control social, económico, y político"19, dominando en espacios "posmodernos" del interior del país, llenan el vacío de estado o del empresariado nacional, explotando economías ilegales, depredadores del medio ambiente, al mismo tiempo que incrementan la corrupción, intervienen la democracia.

Otro concepto presente en la investigación es el de Posconflicto ${ }^{20}$. Lo abordamos en la medida que su uso se extendió para denominar al ciclo histórico que siguió a la desmovilización de las FARC-EP el año 2016, buscando replicar mecánicamente en Colombia realidades de otros países en Centroamérica, África o Europa. Desde el punto de vista teórico, entendemos el posconflicto como la desactivación de actores no estatales en un conflicto armado, la recuperación del monopolio de la fuerza del Estado, el silencio de los fusiles, junto a la disminución de las cifras de la violencia, los homicidios, heridos y los secuestros. Es decir, el fin del "continuum de la violencia"21.

Ejemplos históricos de escenarios donde se ha configurado un posconflicto en el siglo XX, son El Salvador, Guatemala e Irlanda del Norte luego del acuerdo de "Viernes Santo" entre otros. Con este concepto se daría cuenta de una situación de salida o de superación de la guerra, puesta en marcha de una justicia transicional (la Justicia Especial para la Paz o JEP en el caso colombiano), la reinserción de excombatientes, apoyos políticos, institucionales y ciudadanos, entre otros aspectos $^{22}$. El posconflicto es conceptualmente el período que sigue a la superación total o parcial a los conflictos armados, cuando el número

19 Carlos Medina, Mafia, narcotráfico y bandas criminales en Colombia; Ciro Krauthausen, "Poder y Mercado. El narcotráfico colombiano y la mafia italiana", Nueva Sociedad 130 (1994): 112-125.

20 Cabe mencionar que en modo alguno este trabajo se centra en el debate académico de este concepto, con el cual se ha caracterizado el período histórico colombiano tras la desmovilización de las mayores entidades aradas insurgentes y contrainsurgentes.

21 Nancy Scheper Hughes, La muerte sin llantoviolencia y vida cotidiana en Brasil, 305.4 S3, 1997.

22 Tito Hernando Pérez Pérez, "Conflicto y posconflicto en Colombia: una mirada a la política de seguridad democrática”, Magistro Vol. 5 No. 10 (2011): 129-150. 
de homicidios disminuye y se comienza a hablar de la construcción de la paz y supeditado a la ausencia de guerra, aunque no a la paz absoluta ${ }^{23}$.

Nos parece que no es posible utilizar un relato lineal en Colombia que pase del conflicto al posconflicto dada su larga trayectoria, complejidad de elementos causales, y los vacíos institucionales de un Estado que se consolida a fuerza de exclusiones ${ }^{24}$. Se crea la ilusión a nivel nacional e internacional de que se están acabando las formas tradicionales de violencia, pero lo que ocurre es "que se abre otra fase conflictiva y de mucha incertidumbre" 25 y los actores del pasado, que sostenían discursos políticos insurgentes y contrainsurgentes se han criminalizado del todo ${ }^{26}$.

Desde el punto de vista económico, el conflicto armado y el crimen organizado ha sido investigado por vez primera por Vilfredo Paretto en $1999^{27}$. Para este autor, el conflicto armado debe ser entendido como una pugna por la distribución de la producción, cuyo efecto es que desvía recursos de entidades productivas hacia improductivas ${ }^{28}$. Los estudios empíricos más conocidos al respecto son los de Rubio 1995, Parra 1998, Arias y Ardila 2003, Vargas 2003, Cárdenas 2007, y Zenteno $2007^{29}$. El papel como actores de la economía de las organizaciones criminales y su impacto político y para el desarrollo, ha sido analizado en los trabajos de Daron Acemoglu (2013) ${ }^{30}$, para la mafia siciliana, los paramilitares y guerrillas de Colombia. Afirma que, en el mediano y largo plazo las organizaciones criminales, afectan la acción política del estado, el desarrollo económico y los procesos democráticos.

23 Diaz, Raquejo, y Mateus, "Posconflicto colombiano y sus efectos económicos".

24 Fals Borda, Germán Guzmán Orlando, y Eduardo Umaña, La violencia en Colombia (Bogotá: Tercer Mundo, 1962).

25 Ariel Ávila y León Valencia, Los retos del posconflicto: Justicia, seguridad y mercados ilegales (Bogotá: Ediciones B, 2016).

26 Patricio García Pérez, "Organizaciones armadas post Autodefensas Unidas de Colombia: Del pasado contrainsurgente al presente de criminalidad transnacional. 2006-2016”, Izquierdas No. 49 (2020): $141-158$.

27 Jorge Restrepo y Aponte Castro, Guerra y violencias en Colombia: herramientas e interpretaciones (Bogotá: Editorial Pontificia Universidad Javeriana, 2009).

16228 Jorge Restrepo y Aponte Castro, Guerra y violencias en Colombia.

29 Jorge Restrepo y Aponte Castro, Guerra y violencias en Colombia.

30 Daron Acemoglu, James A. Robinson, y Rafael J. Santos, "The monopoly of violence: Evidence from Colombia", Journal of the European Economic Association 11 (2013): 5-44. 
Estos estudios empíricos no han estado ausentes de inconvenientes cuantitativos como son la existencia de variables omitidas relevantes, causalidad reversa y las dificultades para medir actividades ilegales o niveles de conflictividad ${ }^{31}$. Los mecanismos por los cuales se produce el impacto negativo del crecimiento suelen ser vía pérdida de productividad, destrucción de trabajo y capital humano, sustitución de gasto social por gasto militar e inadecuada asignación de recursos ${ }^{32}$. Dentro de los trabajos más recientes, destaca el aporte de Restrepo, Moscoso y Villa los cuales, utilizando una metodología de modelo estructural y datos entre 1988 y 2009 concluyen que el aumento de actividades ilegales, la disminución del gasto público y el aumento de conflicto armado llevan a disminuir el crecimiento económico ${ }^{33}$. Sin embargo, al momento de escribir este artículo (2019) no se ha hecho ninguna medición similar para el período del llamado, posconflicto, tras los acuerdos de Paz del año 2006.

\section{Actores armados del conflicto, AUC, FARC-EP, unA VEZ DESMOVILIZADOS. BALANCE DE UNA DÉCADA DE FRACASO INSTITUCIONAL (2006-2016).}

Consideramos de modo particular en la investigación a los grupos armados que tienen heredades en las dos mayores entidades armadas de los años 90, AUC y FARC-EP, las cuales han sido partes de procesos de desarme, desmovilización y reinserción dentro de matrices institucionalmente construidas entre los años 2005-2016. Los grupos armados e ilegales que actúan luego del año 2006, son fragmentarios, residuales, variados en su origen, tamaño y localización, su motivación se orienta al control de economías ilegales, territorios donde se producen, carecen de motivaciones políticas e ideológicas visibles, afectan la vida de la población, combaten por el control de mercados de la violencia, atacan a los dirigentes sociales, y han llegado a contar con el apoyo de políticos,

31 Edgar Villa, Manuel Moscoso, y Jorge Restrepo, "Crecimiento, conflicto armado y crimen organizado: Evidencia para Colombia”, Vniversitas Económica Vol. 13 No. 3 (2012).

32 Mauricio Santamaría, Norberto Rojas Delgadillo, y Gustavo Hernández Díaz, “Crecimiento económico y conflicto armado en Colombia” (Departamento Nacional de Planeación, 2013).

33 Por ejemplo, estiman que el incremento de homicidios o secuestros de un 1\% reducen el PIB departamental en promedio entre un $0,04 \%$ y un $0,36 \%$. 
empresarios e integrantes de la fuerza pública. Se trata de pandillas, bandas locales (La Empresa de Buenaventura), combos, herederos de carteles (Los Rastrojos, Oficina), guerrillas como ELN, y disidencias del EPL, por ejemplo.

Los actores armados de la extensa historia del conflicto colombiano son diversos. Nos interesan sobre todo en este trabajo, los de tipo paraestatal y contraestatal ${ }^{34}$, cuyas máximas expresiones fueron las AUC, y la guerrilla de las FARC-EP. Ambas protagonizaron de modo estelar el período más activo de la violencia del siglo XX, temporalmente demarcado en la década de los 90. Las $\mathrm{AUC}^{35}$, fueron la mayor organización paramilitar de la historia colombiana, que aspiró a aglutinar jerárquicamente y federalizar estructuras de autodefensas repartidas en la fragmentada geografía colombiana. Tributarias de la Guerra Fría, estuvo apoyado por partes del Estado fue sostenida por élites locales y regionales refractarias a las reformas democráticas que impulsaba el Estado central y a negociaciones de paz con la guerrilla desde mediados de los 80. Levantaron una brutal y exitosa política de expansión territorial, captura del estado, apropiación y concentración de la tierra ${ }^{36}$. Al mismo tiempo que desarrollaban el control y comercialización de la cocaína.

El Presidente Uribe implementó negociaciones y acuerdos con las AUC tendientes a su desmovilización a partir del año 2003, modificando la ley 418 que le impedía desarrollar acuerdos con actores fuera de la Ley, promoviendo la ley 782.El 23 de noviembre del año 2003, el proceso se institucionalizó, a través de la Ley 975 llamada de "Justicia y Paz", publicada en el "Diario Oficial” de Colombia el 25 de julio del año 2005. Los datos oficiales señalan que entre el 2003 y el 2006 se desmovilizaron 36 estructuras de las AUC y 31.671 combatientes entregándose 18.051

34 Conceptualización tomada del trabajo del historiador Carlos Medina Gallego, que permite denominar a los paramilitares y las guerrillas por sus posturas de defensa o beligerancia ante el Estado.

35 García Pérez, "Organizaciones armadas post Autodefensas Unidas de Colombia".

36 Edward Gibson, "Subnational Authoritarianism: territorial strategies of political control in democratic regimes", en Annual Meeting of the American Political Science Association, vol. 2, 2004; Claudia López, "Y refundaron la patria... De cómo mafiosos y políticos reconfiguraron el Estado colombiano”, Bogotá: Debate, 2010. 
armas. La reincidencia de los combatientes de las AUC desmovilizados fue de 18\% de acuerdo a la Agencia Colombiana de Reintegración.

El año 2006 se conocieron las primeras alertas en torno al fenómeno de reaparición de grupos armados organizados, una vez culminada la desmovilización de las AUC. Estas alertas provinieron del periodismo de opinión y denuncia ${ }^{37}$ y en ellos se exponían las denuncias recogidas entre la población, debido al recrudecimiento de acciones violentas en departamentos del país que habían estado bajo el control y dominio del paramilitarismo ${ }^{38}$. Para el Estado colombiano, las formas de violencia privada que emergieron en distintos departamentos y municipios, no correspondían a continuidades o nuevas formas de paramilitarismo. Se trataba de un fenómeno de carácter criminal, que por lo tanto debía enfrentársele a través del accionar policial, haciendo valer el monopolio de la fuerza estatal, y de la institucionalidad. El Gobierno de Uribe, estableció la denominación genérica de "Bandas Criminales "o Bacrim, ratificando su visión de que en Colombia no existía un conflicto interno, sino una guerra contra el terrorismo y los grupos ilegales. El año 2007, dictó además, la "Política de consolidación de la seguridad democrática", con el objetivo de desmantelar a las bacrim, lo que fue complementado por el Decreto 2374 del año $2010^{39}$.

Durante el segundo gobierno de Santos, y ante el crecimiento de la acción de los grupos armados, se impulsaron acciones legales y armadas para enfrentarlas. Entre las más importantes, se debe mencionar el Decreto No2314 del 1 de julio del año 2010 que creó una Comisión Interinstitucional integrada por 8 personas y presidida por el Ministro del Interior y Justicia, "contra las Bandas Criminales y se dictan disposiciones" ${ }^{40}$. El Gobierno promovió, además, el año 2016, una nueva caracterización del fenómeno atendiendo a su complejidad y diversidad. Así distinguió a los “Grupos Armados Organizados" o GAO, definidos

\footnotetext{
37 Revista Cambio, "Reciclaje para”, Edición N 676 (12 de junio del año 2006).

38 García Pérez, "Organizaciones armadas post Autodefensas Unidas de Colombia”.

39 María Andrea García Ruiz, Ángela María Silva Aparicio, y Marcela Julieth Magallanes Montoya, "Políticas para combatir a los grupos armados posdesmovilización en los gobiernos de Álvaro Uribe Vélez y Juan Manuel Santos”, Análisis político Vol. 31 No. 92 (2018): 159-179.

40 Ministerio del Interior y Justicia, Decreto $N^{\circ} 2374$ de 1 de julio de 2010 y Patricio García “Organizaciones armadas Post Autodefensas Unidas de Colombia” 2020, 141-158.
} 
como "organizaciones que bajo la dirección de un mando responsable ejerzan sobre una parte del territorio un control tal que les permita realizar operaciones militarmente sostenidas y concertadas". Por su parte, los Grupos Delictivos Organizados, GDO fueron definidos como una "estructura de 3 o más personas que existe durante cierto tiempo y que actué concertadamente con el propósito de cometer uno o más delitos graves" ${ }^{41}$. Sin embargo, no todos estaban de acuerdo con la visión y análisis del gobierno respecto a la desaparición del paramilitarismo en Colombia. Hubo intelectuales, académicos, ONGs y organizaciones internacionales que afirmaban que se estaba ante una nueva forma de paramilitarismo criminalizado. El "Instituto de Estudios sobre Paz y desarrollo" (INDEPAZ), las denominó "narcopamilitares" u organizaciones de tipo "ejércitos privados", que buscan el control de medios y factores económicos para el enriquecimiento de sus líderes ${ }^{42}$, que en ocasiones se presentan como fuerzas del orden y protectores de megaproyectos ${ }^{43}$. Se coincidía en que se trataba de formas de paramilitarismo criminalizado, rearmado o reorganizado ${ }^{44}$.

Se consideran en el trabajo a los actores criminales tratados, también como resabios y disidencias de la guerrilla de las FARC-EP. La producción académica acerca de las guerrillas ${ }^{45}$ y sobre todo acerca de las FARC-EP, son numerosos y variados, en estos se exponen sus orígenes, bases sociales, ofensivas del Gobierno de Uribe y la política de seguridad democrática (sobre todo el Plan Patriota).

La criminalización de formaciones guerrilleras, rearmados, tienen como causa de origen, los incumplimientos del Gobierno con los acuerdos

41 Ministerio del Interior y Justicia colombiano Decreto 2374.

42 Camilo González Posso, “¿Hacia la dejación de las armas y el sometimiento del Clan del Golfo?”, Informe XIII sobre narcoparamilitares y grupos armados en el posacuerdo (Unidad de Investigación, Bogotá D.C.: INDEPAZ, octubre de 2017).

43 Posso. “¿Hacia la dejación de armas", 1-9.

44 Para conocer el debate respecto de las continuidades del paramilitarismo luego del año 2006 se puede ver García Pérez, "Organizaciones armadas post Autodefensas Unidas de Colombia”.

45 Señalamos de modo particular a las FARC-EP como actor del posconflicto. Hay trabajos importantes acerca de otras guerrillas como el ELN y el M-19 en Darío Villamizar "Las Guerrillas en Colombia" y sobre el EPL en Álvaro Cepeda y Jorge Rojas "A las puertas del Ubérrimo" (Grupo Zeta, 2014). 
de paz firmados el año $2016^{46}$. El escenario para los acuerdos fue La Habana, y el resultado se materializó en la firma del "Acuerdo final para la terminación definitiva del Conflicto" firmado el 24 de noviembre del año 2016. En este, se suscribieron 6 puntos de acuerdo: la cuestión agraria, la participación política y formación del partido FARC-EP, drogas ilícitas, víctimas, fin del conflicto e implementación. En el plebiscito de aprobación ciudadana de inicios de octubre del año 2016, más del 50\% de la población los rechazó, asestándole un golpe irreparable al tratado y abriendo la ventana a la posibilidad de mutaciones y continuidades de los actores armados.

Así mismo hubo integrantes de la organización guerrillera que nunca se acogieron al proceso de paz (disidentes) o que se separaron de éste (rearmados).Seha evidenciado en el accionarde estas estructuras armadas la pérdida de motivaciones estrictamente políticas. Así, por ejemplo, las llamadas "disidencias", realizan acciones económicas ilegales en la Amazonía, en regiones fronterizas y al interior de Venezuela, también en el pacífico colombiano. En ese sentido, para la publicación de investigación del crimen organizado "Insigth Crime" las mutaciones y continuidades de las FARC-EP del tipo rearmados, residuales o disidencias pueden ser conceptualizadas como "ExFARC-EP mafia" ${ }^{47}$ por el abandono de ideales revolucionarios y su reemplazo por actividades criminales.

Sólo el "Frente 1 "Armando Ríos" localizado en las selváticas regiones de Guaviare, Vaupés y Guanía, desde el inicio manifestó su voluntad de no acogerse a los acuerdos de paz, grupos como este, rearmados, han crecido desde el primer año del Gobierno del presidente Duque. De los 300 municipios en que operaban las FARC-EP el primer semestre del año 2019, en 85 hay presencia de las disidencias el año 2018 y en 36 del ELN ${ }^{48}$. De acuerdo a Fiscales de la Dirección de apoyo a la

46 Verdad Abierta, "Disidencias de las FARC-EP, una realidad prevista", accedido 30 de septiembre de 2020, https://verdadabierta.com/disidencias-de-las-farc-una-realidad-prevista/.

47 "Ex-FARC Mafia - Crónica de una amenaza anunciada - Investigation”, InsightCrime. (blog), accedido 30 de septiembre de 2020, https://es.insightcrime.org/investigaciones/ex-farc-mafia-cronica/.

48 "Iván Márquez ha estado en diálogos con la disidencia arada de las FARC-EP" Ariel Ávila Semana, 28 de agosto de 2019. 
Investigación y Análisis contra la criminalidad organizada, el año 2018, las "disidencias" de las FARC-EP contabilizaban 1.463 integrantes con presencia en 18 departamentos, 120 municipios, y 2.432 veredas $^{49}$ de Colombia. El accionar evolutivo de las disidencias guerrilleras, desdibuja la diferencia entre guerra y crimen organizado, desarrollando acciones de violencia por motivos particulares sobre todo de tipo económicos $^{50}$. Considerado históricamente, no es el primer proceso de paz dificultoso o fallido en que participó las FARC-EP. Se debe recordar el de 1984-85(La Uribe), 1990-91 y 1998, por señalar los tres últimos ${ }^{51}$.

\section{Actores armados del pasado conflicto y Organizaciones CRIMINALES ACTUALES}

De acuerdo a la convención de las Naciones Unidas, las organizaciones del crimen organizado, las organizaciones criminales, pueden ser bien definidas como "un grupo bien estructurado de 2 o más personas de permanencia y actuación concertada con el propósito de cometer uno o más delitos" ${ }^{\prime 2}$. Sus operaciones se realizan a nivel transnacional, para lo cual establecen alianzas con los carteles mexicanos, principales actores hoy en día del negocio de las drogas, u organizaciones criminales de Brasil. Este trabajo considera particularmente a las organizaciones de pasado paramilitar, debido que los 13 años transcurridos desde su desmovilización permiten acceder a una mayor variedad de evidencias y fuentes para sustentar la hipótesis de este trabajo. En el marco de la globalización, las estructuras paramilitares, o de pasado insurgente y sus continuadoras pueden ser caracterizados como "un grupo de

49 El Espctador. Radiografía de las disidencias de las Farc, https://www.elespectador.com/noticias/ judicial/radiografia-de-las-disidencias-de-las-farc/ (accedido 30 de septiembre de 2020).

50 Teófilo Vasquez, "Las nuevas guerras y el conflicto armado en Colombia", Revista Controversia No. 190 (2008): 282-310.

51 En las negociaciones de 1990 con el Presidente Álvaro Barco se desmovilizó parte del EPL, y del todo el M-19, y Quintín Lamé por ejemplo. La del año 80 culminó trágicamente con el exterminio de la Unión Patriótica, expresión política legal de la izquierda con apoyo de las FARC-EP a manos del paramilitarismo y sicarios del narcotráfico.

52 Caviedes Estanislao Escalante-Barreto, "Crimen organizado y problemas dogmáticos de autoría y participación: análisis comparado de Colombia y España en el marco de la lucha contra el delito en la Organización de las Naciones Unidas”, Pensamiento Jurídico, No. 45 (2017): 97-125. 
delincuentes que aúna fuerzas para llevar a cabo un delito específico, es similar a una empresa en la que todos desempeñan simplemente su parte de manera organizada" 53 , que han mejorado la eficiencia de sus actividades delictivas a través de estructuras delictivas transnacionales, pues la globalización ha facilitado el intercambio de bienes ilícitos, "y la consolidación de alianzas entre organizaciones criminales de todo el mundo" 54 .

La categoría analítica que utilizamos, actores criminales o delincuenciales transnacionales ${ }^{55}$ proviene de la Historia de las Relaciones Internacionales y permite caracterizar con mayor rigor a actores no estatales ${ }^{56}$. Un aspecto resaltante de las organizas armadas del posconflicto es su accionar transfronterizo ${ }^{57}$, a diferencia de las organizaciones criminales colombianas de las décadas de los 80 y 90. A nivel oficial, el Gobierno de Colombia, reconoció la existencia de una criminalidad nacional que ha adquirido niveles de acción transnacional.

Así, la canciller María Angélica Holguín, en su exposición ante los asistentes al 60 período ordinario de sesiones de la Comisión de estupefacientes de la ONU en Viena el lunes 13 de marzo del año 2017, dio cuenta de la presencia de organizaciones criminales como el Cartel de Sinaloa, en el bajo Cauca y el Catatumbo: "con enormes sumas de dinero para garantizar la compra de la hoja de coca, ya no estamos enfrentando sólo carteles colombianos sino también extranjeros" "58. A nivel jurídico, hay también denuncias provenientes de la Defensoría del Pueblo y del Fiscal General, acerca de las vinculaciones de las organizaciones criminales colombianas con carteles de la droga mexicanos. En ese sentido, el Defensor del Pueblo Carlos Negret alertó al Gobierno

53 Gambetta, La mafia siciliana.

54 Linares Hamann, "Redes criminales transnacionales".

55 Pereira Castañares, Historia de las relaciones internacionales contemporáneas.

56 Juan Carlos Pereyra "Historia de las Relaciones Internacionales" 40-62.

57 Insight Crime, "Las ex-FARC mafia, Venezuela y el actual clima internacional", accedido 30 de septiembre de 2020, https://es.insightcrime.org/investigaciones/ex-farc-mafia-venezuela-clima-internacional/.

58 Ministerio de Relaciones Exteriores, Intervención de la Canciller María Ángela Holguín en el segmento de alto nivel del 60o Período de Sesiones de la Comisión de Estupefacientes de las Naciones Unidas, Cancillería, 13 de marzo de 2017, https://www.cancilleria.gov.co/newsroom/news/intervencion-canciller-maria-angela-holguin-segmento-alto-nivel-60o-periodo-sesiones (accedido 30 de septiembre de 2020). 
respecto de que; "En Tierralta, Departamento de Córdoba (zona de hegemonía en el pasado de las AUC), ha estado actuando supuestamente el Cartel de Sinaloa que es el que financia bandas como las Autodefensas Gaitanistas" 59 .

Durante la posguerra fría, década de los 90, las amenazas a la paz provinieron de actores no estatales fortalecidos por el control de economías ilegales y que operaban en un contexto donde el Estado ha visto disminuido el monopolio de la fuerza ${ }^{60}$. En la globalización, las amenazas han provenido del terrorismo, el fanatismo religioso, étnico y del crimen organizado. Con ello, las contiendas han dejado de tener un carácter interestatal para pasar a ser "conflictos intraestatales de baja intensidad" ". El año 1995, la Organización de las Naciones Unidas identificó 18 categorías de "delitos transnacionales" incluyendo en el listado el lavado de dineros, las actividades terroristas, el robo de propiedad intelectual, cibercrimen, corrupción y narcotráfico entre otros ${ }^{62}$.

La internacionalización de las organizaciones criminales en Colombia no es un fenómeno nuevo. Se puede señalar como inicio de este, el accionar de los carteles de la cocaína en los años 80 y el control del negocio de las drogas por las AUC en los años 90 e inicios del siglo XXI. En ese período, la internacionalización de las organizaciones criminales apuntó a tres objetivos: la adquisición de armas y tecnología, la expansión y reconversión de utilidades y el ejercicio de violencia fuera de las fronteras ${ }^{63}$. En el marco de la globalización, en cambio, las estructuras armadas de cualquier origen pueden ser caracterizados como "un grupo de delincuentes que aúna fuerzas para llevar a cabo un delito específico, es similar a una empresa en la que todos desempeñan

59 El Colombiano. El Colombiano, Cartel de Sinaloa estaría financiando bandas criminales en Colombia, https://www.elcolombiano.com/colombia/cartel-de-sinaloa-estaria-financiando-bandas-criminales-en-colombia-MI8039691 (accedido 30 de septiembre de 2020).

60 Kaldor, New and old wars.

61 Linares Hamann, "Redes criminales transnacionales"; Kaldor, New and old wars.

62 United Nations Office on Drugs y Crime (UNODC), "Results of a pilot survey of forty selected organized criminal groups in sixteen countries", Global Programme against Transnational Organised Crime UNODC Vienna, 2002.

63 Daniel M. Rico, "Las dimensiones internacionales del crimen organizado en Colombia: Las Bacrim, sus rutas y refugios", Washington, DC, 2013. 
simplemente su parte de manera organizada" ${ }^{4}$, que han mejorado la eficiencia de sus actividades delictivas a través de estructuras delictivas transnacionales, "significativamente armadas que desarrollan tareas de control de los grandes negocios ilícitos como depredación subsidiaria de los mismos" $"$.

La implementación de la violencia para mantener el control territorial y de la población, junto al control de actividades económicas, es un rasgo propio de las organizaciones del crimen organizado que operan en distintos escenarios latinoamericanos, por ejemplo, los carteles mexicanos y brasileños el asociado al tráfico de drogas y las "clicas" de la Mara "Salvatrucha" de El Salvador" ${ }^{66}$ quienes ejercen un "dominio armado" " ${ }^{67}$ del territorio. En ese sentido, se ubican los llamados "Paros armados" llevados a cabo por las "Autodefensas Gaitanistas de Colombia", brazo armado del "Clan del Golfo", que lograron detener las actividades de 6 departamentos el año 2012 y 8 el 2014 ${ }^{68}$. El año 2016, el "paro armado" se desarrolló en 36 municipios del país, y, según la Policía Nacional, el 63\% de los actos de fuerza afectó a la población.

Estas entidades criminales, se configuran y organizan como redes y nodos, Una importante diferencia respecto de estructuras criminales anteriores como cárteles de las drogas y los paramilitares. En este nuevo esquema, las organizaciones de mayor capacidad militar someten o cooptan a las menores, venden franquicias a bandas y pandillas urbanas, configurando un diseño de flexibilidad del tipo empresarial pero criminal. Un ejemplo de la nueva modalidad orgánica es el poderoso "Clan del Golfo", que se impuso sobre las otras organizaciones criminales de Colombia hacia el

64 Gambetta, La mafia siciliana; Gaetano Mosca, Che cosa è la Mafia?, vol. 4 (Il Grano Edizioni, 2015).

65 Juliana Suárez Vanegas, "BACRIM: bandas criminales", Observatorio de Derecho Internacional Humanitario. Bogotá. Recuperado el 26 (2012).

66 Wim Savenije, "Las pandillas trasnacionales o" maras": violencia urbana en Centroamérica", Foro internacional, 2007, 637-659.

67 Ana Paula Mendes de Miranda y Jacqueline De Oliveira Muniz, "Dominio armado: el poder territorial de las facciones, los comandos y las milicias en Río de Janeiro | Voces en el Fenix", Voces en el Fénix, accedido 30 de septiembre de 2020, http://vocesenelfenix.com/content/dominio-armado-el-poder-territorial-de-las-facciones-los-comandos-y-las-milicias-en-r $\%$ C $3 \%$ ADo-de-j.

68 "Urabeños demuestran su poder regional", accedido 30 de septiembre de 2020, https://verdadabierta.com/urabenos-demuestran-su-poder-regional/.“ 
año 2015. Estos, se consolidaron como "un Nodo en el mercado ilegal del Narcotráfico y una organización de tercera generación que funciona en red con nodos territoriales y donde los mandos son reemplazables fácilmente" ${ }^{69}$.En el mando superior, se ubica una "mesa directiva" compuesta por 5 personas que cubren un territorio amplio, seguidos de los llamados "socios" o" 50 mandos, cada uno con un territorio asignado por su Jefe"70 A su vez, los mandos contribuyen con dinero para financiar a la fuerza militar llamada "Autodefensas Gaitanistas de Colombia", fuerza de choque encargada de la seguridad de los jefes y de las operaciones armadas contra competidores como "Los Rastrojos". La organización, está compuesta por un centro y periferias con actividades y composición distintas, que las hace resistente a la acción policial. El centro toma las decisiones importantes (Estado Mayor) mientras que las periferias son flexibles y actúan en terreno, y pueden estar constituida por bandas ya existentes de menor tamaño, las cuales son tercerizadas tipo "outsourcing", en una modalidad de "posfordismo" criminal que les proporciona gran capacidad operativa y comunicaciones internas más fluidas.

\section{BASES ECONÓMICAS DE UN ACTOR CRIMINALIZADO}

La desmovilización incompleta de las AUC en 2006 y una década más tarde de las FARC-EP, sumado a la tardanza en la llegada del Estado a los territorios a través de políticas sociales y desarrollo, sumado al incremento del narcotráfico y la minería ilegal, confluyeron para la conformación de numerosas y fragmentarios grupos armados criminalizados. Tal como lo anticipó Rodrigo Tovar Pupo alias "Jorge 40" líder del Bloque Norte de las AUC, al señalar que "Si el Gobierno no cumple, es claro que surgirán nuevos grupos armados como respuesta a la indiferencia y el olvido del Estado"

69 "La compleja estructura detrás del 'clan del Golfo", Fundación Paz y Reconciliación (blog), 16 de julio de 2018, https://pares.com.co/2018/07/16/la-compleja-estructura-detras-del-clan-del-golfo/.

70 "La compleja estructura detrás del 'clan del Golfo".

71 Semana, Habla 'Jorge 40', Semana.com Últimas Noticias de Colombia y el Mundo, 4 de marzo de 2006, https://www.semana.com/nacion/articulo/habla-jorge-40/77675-3/ (accedido 30 de septiembre de 2020). 
Las bases productivas que permiten el funcionamiento y enriquecimiento de las organizaciones post AUC, se realizan en ámbitos económicos con debilidades institucionales, que llamaremos "espacios ingobernados". Según el departamento de las Naciones Unidas dedicado al estudio del mercado de las drogas (UNOCD), en estas regiones se concentra el $51 \%$ del cultivo de drogas de Colombia ${ }^{72}$. Entre las actividades económicas, más importantes señalamos a la minería del oro. Esta actividad extractiva, se desenvuelve dentro de la ilegalidad en Colombia. Una investigación de la Contraloría General dirigida por Jorge L. Garay (2010), señala que el 63\% de la explotación de oro es ilegal en el país ${ }^{73}$. La Asociación colombiana de minería por su parte, reveló que en el año 2016, Colombia produjo 1,99 millones de Onzas troy, de estas sólo el 13\% venían de explotaciones formales, siendo Antioquia el mayor productor. La producción y las reservas de oro de Colombia son de gran magnitud. Se estima que estos yacimientos tienen reservas probadas de 7 millones de onzas, vale decir, unas 141 toneladas de oro $^{74}$.

Mientras tanto, sigue siendo el narcotráfico el negocio de mayor rentabilidad y tradición criminal de Colombia, y logra concitar en pos de su control a integrantes de estructuras armadas de todo tipo, paramilitares, disidencias guerrilleras, al mismo tiempo que genera recursos para el funcionamiento de organizaciones ilegales. El crecimiento de los cultivos ha dejado en evidencia el fracaso de los planes de erradicación. Este incremento ha incluido a los territorios étnicos y parques nacionales donde por la legislación ambiental, está prohibida la fumigación ${ }^{75} \mathrm{O}$ la implementación de programas para la de sustitución de cultivos ${ }^{76}$. Las áreas cultivadas, han ido aumentando desde el año 2013, para alcanzar los records de 150 mil hectáreas el 2016 y más de 200 mil en 2017. De

72 Rico, "Las dimensiones internacionales del crimen organizado en Colombia". 1-48.

73 El Tiempo, 'La minería criminal va a generar más violencia': Luis Jorge Garay, El Tiempo, 11 de mayo de 2013, https://www.eltiempo.com/archivo/documento/CMS-12793568 (accedido 30 de septiembre de 2020).

74 En el mercado internacional una onza troy de oro se cotiza a 1.293 dólares

75 Hay que considerar que la fumigación con químicos como el glifosato fueron prohibidos el año 2015, debido a los informes de efectos dañinos para las personas presentados por la OMS.

76 Semana, La coca se dispara, https://www.semana.com/nacion/articulo/coca-cultivos-alcanzan-la-cifra-mas-alta-en-la-historia-de-colombia/517424/ (accedido 30 de septiembre de 2020). 
acuerdo al trabajo de Camilo Echandía ${ }^{77}$ ha existido históricamente, una convergencia de las organizaciones armadas en zonas de narcotráfico, y este se ha mantenido en los continuadores de las AUC.

El contrabando, es también una actividad de alta rentabilidad. En primer lugar, de Combustibles. De acuerdo con la Fundación Ecopetrol, el tráfico ilegal recorre la ruta que va desde Monte Lara a Maicao, en La Guajira, Bodillo y Río Seco, en Valledupar, desde donde se distribuye luego a Magdalena y Sur de Bolívar. Cada año entran al país más de 100 millones de litros de gasolina ${ }^{78}$ y las autoridades señalan que cada día ingresan de manera ilegal cerca de tres millones de dólares en combustibles. Por su parte, el Contrabando de Aluminio es otra modalidad de economía ilegal. Según la División de Impuestos y Aduanas de Colombia se ha incrementado el contrabando de aluminio proveniente de Venezuela el año 2017 en un 629\%. En ese país, es adquirido por contrabandistas a 2500 pesos el kilo para ser luego vendido en Colombia en 4500-5000 pesos, todo el negocio está bajo el control de las organizaciones señalas en este trabajo ${ }^{79}$. A estas actividades económicas, se deben agregar el cobro de extorsiones a comerciantes y empresas, el microtráfico, arrendamiento de seguridad, y el papel de las oficinas de cobro.

Las formas de criminalidad consideradas, perfilan a un actor económico del capitalismo colombiano que aprovecha la ausencia de un empresariado que lidere e impulse actividades económicas a partir de bases capitalistas modernas y externalidades económicas positivas en regiones de "frontera interna" e ingobernadas y aprovechan las condiciones de pobreza de la población. Algunas industrias y empresarios lograron manejar el ambiente hostil, haciendo pagos a los bandos en conflicto en los años 90 y primera década del siglo XXI, la estadounidense "Chiquita Brands". Esta multinacional con sede en Cincinatti, que se dedica a la producción y comercialización del banano, hizo pagos a las guerrillas y las AUC entre 1990-2006, para poder continuar con sus operaciones.

77 Camilo Echandía, "Narcotráfico: Génesis de los paramilitares y herencia de bandas criminales", Informes FIP 19 (2013): 5-32. 2016, https://verdadabierta.com/el-oro-negro-del-catatumbo-atractivo-de-los-grupos-ilegales/.

79 El País, Contrabando de gasolina - Venezuela, crimen sin frontera, https://www.elpais.com.co/especiales/venezuela-crimen-sin-frontera/ (accedido 30 de septiembre de 2020). 
Se ha evidenciado otra forma de control económico y territorial realizado por organizaciones armadas del pasado reciente, con apoyo de las políticas de seguridad del Estado y continuada por narcoparamilitares del posconflicto tendientes a consolidar un capitalismo de tipo criminal. Es el caso de Palmero en Chocó estudiado por Marco Palacios $(2019)^{80}$. En este ejemplo el desarrollo de la exportación de aceite de palma en la zona del Chocó fue posible a través del accionar de Bloques paramilitares de las AUC (Elmer Cárdenas), y líderes destacados como Vicente Castaño, y Freddy Rendón. Para ello se expulsó a través de la violencia a la población afro, colaborando a la concentración de la tierra y el impulso de actividades económicas orientadas a la exportación de materias primas por formaciones criminales.

En consecuencia, hay evidencias de que las organizaciones criminales en general impulsan un diseño económico de alta rentabilidad, de propiedad privada en los medios de producción, de control, despojo y desplazamiento de la población campesina. Acorde al capitalismo moderno, desarrollan formas de trabajo que combina el uso intensivo como en la minería o en fases de la cadena del narcotráfico con el trabajo flexible o informal en el sicariato o el microtráfico. En un símil criminal de "desfragmentación productiva", en el cual las organizaciones colombianas, controlan los ámbitos económicos donde se garantiza el mayor valor del bien, como en la producción y elaboración de la cocaína, externalizando la distribución del producto para cubrir de modo eficiente y especializado la oferta global.

\section{LA RELACIÓN DE LOS ACTORES CRIMINALES DEL POSCONFLICTO CON EL CRECIMIENTO ECONÓMICO: UN ESTUDIO INICIAL A NIVEL DEPARTAMENTAL}

En este apartado se estudia a nivel empírico, la existencia de una relación negativa entre la violencia de los actores armados, los factores de riesgo y del crecimiento económico. Los factores de riesgo estudiados son: debilidades institucionales del Estado, continuidad de grupos armados,

80 Marco Palacios, "Criminal Businessmen, Commodity Frontiers and the Colombian State", Journal of Applied Business and Economics Vol. 21 No. 6 (2019). 
e incremento de economías ilegales. Para una aproximación a esta relación se propone estudiar el comportamiento de seis departamentos considerados objetivamente de mayor violencia y actuación de entidades criminales. De ese modo se permite focalizar el análisis en 6 zonas que en la actualidad son descritas como de alto nivel de conflicto.

Con el propósito de estudiar el comportamiento dentro de este conglomerado proponemos estudiar dos grupos caracterizados según su nivel de exposición al riesgo. Definimos entonces "Riesgo Medio" a los departamentos del Cauca, Norte de Santander y Córdoba; mientras que denominamos como "Riesgo Alto" a los departamentos de Putumayu, Chocó y Arauca. Para el resto de los departamentos de Colombia, se le asignará a un grupo denominado "No Seleccionados". Como se discute más adelante, el análisis empírico justifica esta clasificación.

Se utilizan tres análisis empíricos para estudiar la importancia de los factores sobre el crecimiento: test de medias, análisis gráfico, y análisis de correlación de Pearson. A través de estos, aportamos evidencia en torno a que para el posconflicto, o el período posterior al año 2016, el crecimiento económico podría ser explicado a través de factores de riesgo de la hipótesis. Metodológicamente, para el análisis se utilizará como medida el PIB departamental anual entre 2000-2016, para medir crecimiento económico ${ }^{81}$. Por su parte, los factores de riesgo serán medidos a través de proxies a nivel departamental y anual entre 2006-2016 $6^{82}$. Para medir fortaleza institucional del Estado usamos cuatro variables a nivel departamental y anual: (i) Gasto Público per cápita (ii) Cobertura neta de educación ${ }^{83}$ (iii) Cobertura promedio de energía eléctrica rural y (iv) Cobertura promedio de acueductos.

De manera complementaria, la fortaleza y presencia del Estado también se asocia a su capacidad de proveer y garantizar el acceso a servicios básicos a nivel local, es decir, a su densidad ${ }^{84}$. En ese sentido, las cober-

82 La diferencia con el año de inicio del PIB departamental está en la incapacidad de obtener las series de factores de riesgo al nivel departamental.

83 Porcentaje de estudiantes matriculados en el sistema educativo descontando los que están en extra-edad.

84 Juan Pablo Murillo, "El índice de densidad del Estado como una categoría para el análisis de la mor- 
turas estatales, como (ii), (iii) y (iv), permiten obtener una mejor medición de la densidad del Estado ${ }^{85}$. Para medir la variación de conflicto armado utilizamos las tasas de secuestros y homicidios cada 100.000 habitantes a nivel departamental y anual. La literatura sobre el tema ha mostrado que es un buen proxy ${ }^{86}$. Los mayores niveles de homicidios y secuestros están asociados a mayores acciones de grupos al margen de la ley. Por último, la medición de economías ilegales se mide en relación a la producción de narcóticos ilícitos. Para ello, usamos el porcentaje de hectáreas producidas de cocaína del departamento ${ }^{87}$.

En la Tabla 1 resumimos las variables a utilizar y la fuente de los datos.

Tabla 1

Variables proxies a utilizar y fuente de datos de obtención.

\begin{tabular}{|l|l|l|l|}
\hline $\begin{array}{l}\text { Dato, años y objetivo } \\
\text { de medición. }\end{array}$ & \multicolumn{1}{|c|}{ Fuente } & $\begin{array}{l}\text { Dato, años y objetivo de } \\
\text { medición. }\end{array}$ & \multicolumn{1}{|c|}{ Fuente } \\
\hline $\begin{array}{l}\text { PIB pér cápita (2000- } \\
\text { 2017). Producto y creci- } \\
\text { miento económico. }\end{array}$ & $\begin{array}{l}\text { DANE. TerriDa- } \\
\text { ta. Economía. }\end{array}$ & $\begin{array}{l}\text { Cobertura de acueductos } \\
(2008-2016) \text {. Fortaleza } \\
\text { estatal. }\end{array}$ & DANE. \\
\hline $\begin{array}{l}\text { Gasto operacional y de } \\
\text { capital } \\
\text { (2006-2016). Tamaño } \\
\text { del Estado. }\end{array}$ & $\begin{array}{l}\text { DANE. Terri- } \\
\text { Data. Finanzas } \\
\text { Públicas. }\end{array}$ & $\begin{array}{l}\text { Homicidios. Intensidad } \\
\text { conflicto armado. }\end{array}$ & $\begin{array}{l}\text { Estadísticas Vita- } \\
\text { les de la DANE }\end{array}$ \\
\hline $\begin{array}{l}\text { Cobertura neta de } \\
\text { educación (2006-2016). } \\
\text { (Proxy Fortaleza del } \\
\text { Estado). }\end{array}$ & $\begin{array}{l}\text { Ministerio de } \\
\text { Educación Na- } \\
\text { cional }\end{array}$ & $\begin{array}{l}\text { Secuestros. Intensidad } \\
\text { conflicto armado. }\end{array}$ & DANE. \\
\hline $\begin{array}{l}\text { Cobertura energía eléc- } \\
\text { trica rural (2011-2016). } \\
\text { (Proxy Fortaleza del } \\
\text { Estado). }\end{array}$ & $\begin{array}{l}\text { UPME Colom- } \\
\text { bia. }\end{array}$ & $\begin{array}{l}\text { Producción cocaína en } \\
\text { hectáreas producidas } \\
\text { (2006-2016). Variación } \\
\text { economías ilegales }\end{array}$ & $\begin{array}{l}\text { Observatorio } \\
\text { de Drogas de Co- } \\
\text { lombia. }\end{array}$ \\
\hline
\end{tabular}

talidad infantil en el Perú: Un análisis exploratorio”, en Anales de la Facultad de Medicina, vol. 78 (UNMSM. Facultad de Medicina, 2017), 326-332.

85 Murillo. "Índice de densidad del Estado".

86 Santamaría, Delgadillo, y Díaz, "Crecimiento económico y conflicto armado en Colombia”, 2013.

87 Se calculan dividiendo las hectáreas de cada departamento destinados a plantación de cocaína por las hectáreas totales de superficie del departamento. 
Para justificar que el grupo de los seleccionados (Riesgo Alto y Medio) son estadísticamente diferentes del grupo no seleccionado presentamos estadística descriptiva y test de medias. La hipótesis del test consiste considera que los grupos tienen iguales niveles en las variables descritas. En la Tabla 2 se presentan observaciones (1) y (2), medias muestrales en (3) y (4), diferencia de medias (5), desviación estándar de la diferencia (6), y en (7) el estadístico t. La columna (8) muestra los valores-p del test. Los resultados del test sugieren que los grupos comparados son significativamente distintos entre sí en Secuestros, Homicidios, Hectáreas de Cocaína, los tres tipos de cobertura y PIB al 99\% de confianza ${ }^{88}$. Concluimos que la categorización realizada tiene justificación empírica. Además, la intensidad medida como el promedio de los factores de riesgo es mayor en los seleccionados.

Tabla 2

Test t para medias entre grupo seleccionado (Riesgo 1 y 2) y no seleccionado. Años 2006-2016

\begin{tabular}{|c|c|c|c|c|c|c|c|c|}
\hline & $\begin{array}{c}\text { (1) } \\
\text { Obs. } \\
\text { No Sel. }\end{array}$ & $\begin{array}{l}(2) \\
\text { Obs. } \\
\text { Selec. }\end{array}$ & $\begin{array}{c}(3) \\
\text { Media } \\
\text { No Sel. }\end{array}$ & $\begin{array}{l}(4) \\
\text { Media } \\
\text { Selec. }\end{array}$ & $\begin{array}{c}(5) \\
\text { Diff } \\
3-4\end{array}$ & $\begin{array}{l}(6) \\
\text { Desv. } \\
\text { Est. }\end{array}$ & $\begin{array}{c}\text { (7) } \\
\text { Diff/Desv. }\end{array}$ & $\begin{array}{c}(8) \\
\text { P-value }\end{array}$ \\
\hline Tasa Secuestros & 324 & 72 & ,743 & 2,625 & $-1,883$ & ,221 & $-8,5$ & 0 \\
\hline Tasa Homicidios & 324 & 72 & 20,698 & 35,785 & 15,086 & 2,616 & $-5,75$ & 0 \\
\hline $\begin{array}{l}\text { \% Hectáreas } \\
\text { Cocaína }\end{array}$ & 180 & 72 & ,0735 & ,212 &,- 1385 & ,0305 & $-4,55$ & 0 \\
\hline $\begin{array}{l}\text { Gasto público } \\
\text { per cápita }\end{array}$ & 324 & 72 & 1,798 & 1,765 & ,034 & ,112 & ,3 & ,765 \\
\hline $\begin{array}{l}\text { Cobertura } \\
\text { promedio de } \\
\text { acueductos }\end{array}$ & 270 & 60 & 61 & 55,575 & 5,426 & 2,294 & 2,35 & ,018 \\
\hline $\begin{array}{l}\text { Cobertura } \\
\text { promedio de } \\
\text { Electricidad } \\
\text { rural }\end{array}$ & 161 & 36 & 88,148 & 82,304 & 5,843 & 2,26 & 2,6 & ,011 \\
\hline $\begin{array}{l}\text { Cobertura neta } \\
\text { de educación }\end{array}$ & 324 & 72 & 84,494 & 80,844 & 3,651 & 1,183 & 3,1 & ,002 \\
\hline PIB & 312 & 72 & 17,216 & 7,292 & 9,924 & 2,663 & 3,75 & 0 \\
\hline
\end{tabular}

Nota: Asumiendo varianzas iguales. Los grupos son construidos entre seleccionados (Riesgo 1 y 2, es decir Cauca, Norte de Santander, Arauca, Córdoba, Choco y Putumayu.). Tasas homicidios y secuestros son cada 100.000 habitantes, coberturas son porcentajes de la población y PIB millones de pesos colombianos.

88 El nivel de confianza $0 \%$ se puede obtener a partir del valor-p, que se puede interpretar como el valor de (Error de Tipo I). Por ejemplo, en secuestros el nivel de confianza estimado corresponde a 100\%. 
Para estudiar la evolución de las variables en el tiempo se grafican series para los períodos disponibles en la data. La Figura 1 propone estudiar la evolución del PIB departamental a nivel anual. La mayoría de los departamentos seleccionados, es decir, Cauca, Norte de Santander, Córdoba y Arauca presentaban una tendencia al alza similar entre el 2005 a 2006, año donde comienzan a producirse las primeras divergencias. Luego, el promedio departamental experimentó en los siguientes años tasas de crecimiento no sólo de mayor nivel que los departamentos seleccionados, sino también, fue de manera sostenida.

En cambio, departamentos como Putumayu, Chocó y Arauca (Riesgo Alto) divergieron fuertemente incluso con tasas de crecimiento negativas y con una importante situación de estancamiento, mientras que Cauca, Norte de Santander y Córdoba (Riesgo Medio) si bien se mantuvieron al alza se mantuvieron bajo la tasa de crecimiento promedio a nivel departamental. Esto podría entenderse como un pobre rendimiento relativo del grupo de departamentos seleccionados con respecto al promedio departamental.

Figura 1

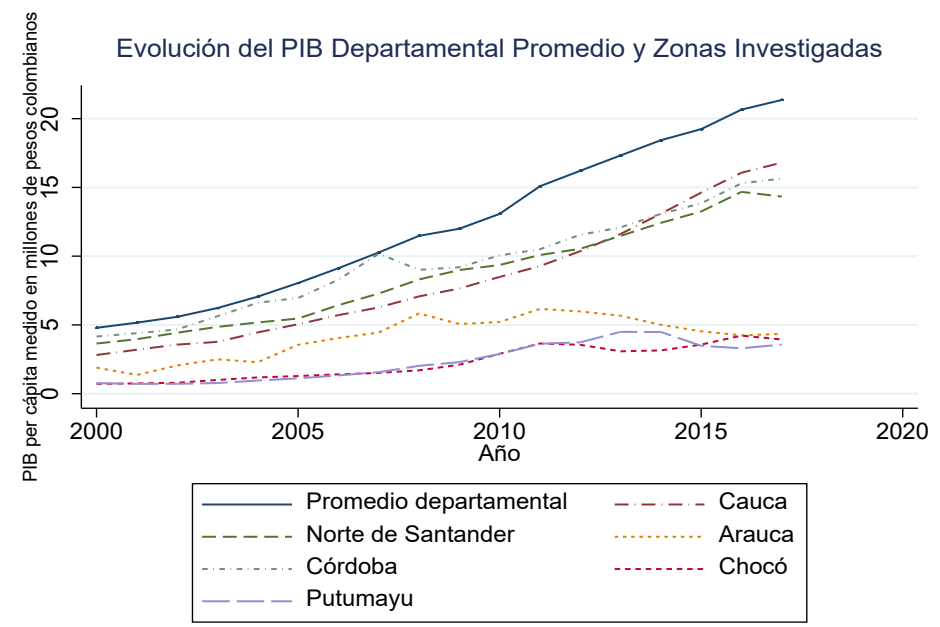

Fuente: Elaboración Propia a partir de la DNP. Los departamentos seleccionados han sido elegidos pues presentan hoy en día altas tasas de problemáticas relacionadas al conflicto armado. 
En las figuras 2 y 3 mostramos la tendencia en la evolución de los homicidios y secuestros desde el 2006-2016 comparando los grupos mencionados. Se puede notar que ambos grupos de riesgo presentan mayor intensidad de homicidios y secuestros respecto al comportamiento promedio departamental. El comportamiento también es más intenso en homicidios y secuestros para el definido como "Riesgo Alto". En la Figura 4 observamos que la intensidad de producción de cocaína en ambos grupos de riesgo desde 2006 en adelante ha sido mayor al promedio departamental, y en los últimos años incluso mayor para Riesgo Medio. Esto muestra empíricamente que estas zonas efectivamente se ven más afectadas por el conflicto y que no se ve en ningún momento una tendencia a la disminución de los factores de riesgo, más bien, en general estos factores irían al alza durante el período estudiado. Analizando la fortaleza del Estado se observa en la Figura 5 se observa la evolución del Gasto Público, la cual ha sido bastante similar entre los grupos entre 2005-2016. Sin embargo, se produjo un importante aumento en Riesgo Alto entre 2012-2016. Esto puede deberse a alguna política pública enfocada en zonas de Riesgo Alto.

En la Figura 6 se presenta la cobertura de electrificación y acueductos. En electrificación el grupo seleccionado parece estar mejor que el promedio departamental. En cambio, en los acueductos Riesgo Medio está peor que el promedio.

En la Figura 7 se observa cómo Riesgo Alto presenta niveles de cobertura de educación muy menores a Riesgo Medio y el Promedio Departamental. Lo anterior, sugiere que en cobertura de educación y acueductos los grupos de Riesgo presentarían diferencias importantes con el resto de los departamentos, lo que sugeriría la ausencia relativa del Estado en estas dimensiones. 


\section{Figura 2}

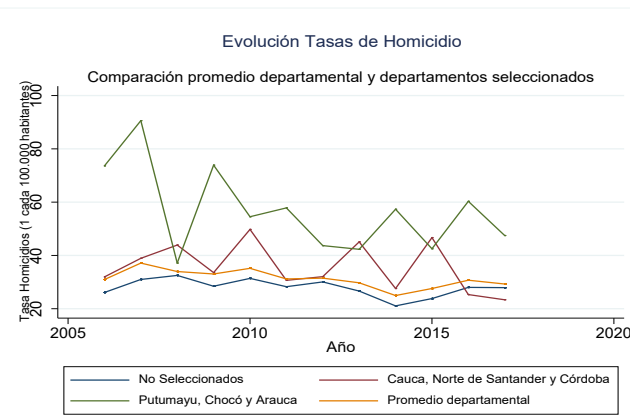

Fuente: Elaboración Propia a partir de Estadísticas Vitales, DANE. Los departamentos seleccionados han sido elegidos pues presentan hoy en día altas tasas de problemáticas relacionadas al conflicto armado.

\section{Figura 4}

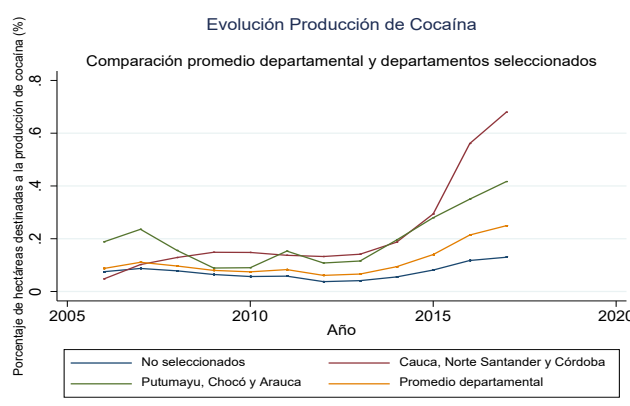

Fuente: Elaboración Propia a partir del Observatorio de Drogas Colombia. Los departamentos seleccionados han sido elegidos pues presentan hoy en día altas tasas de problemáticas relacionadas al conflicto armado.

\section{Figura 6}

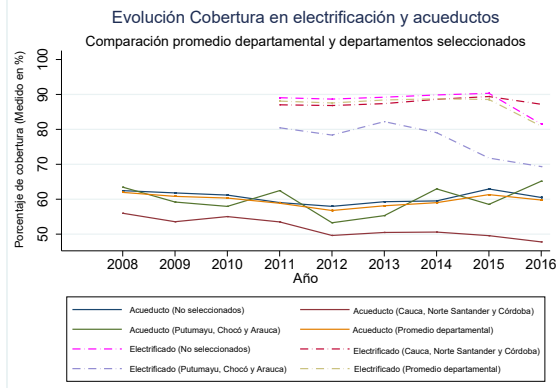

Fuente: Elaboración Propia a partir de UPME y DNP. Los departamentos seleccionados han sido elegidos pues presentan hoy en día altas tasas de problemáticas relacionadas al conflicto armado.
Figura 3

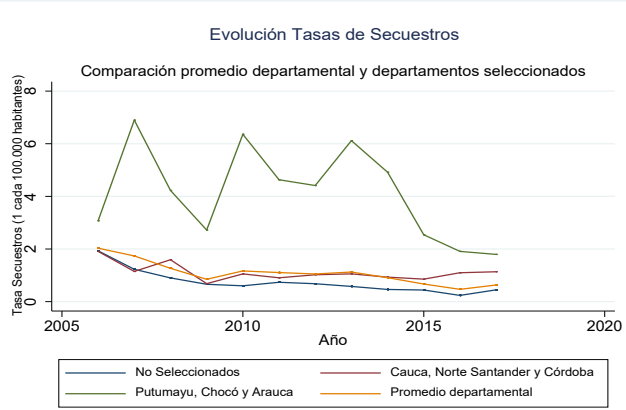

Fuente: Elaboración Propia a partir de la DANE. Los departamentos seleccionados han sido elegidos pues presentan hoy en día altas tasas de problemáticas relacionadas al conflicto armado.

\section{Figura 5}

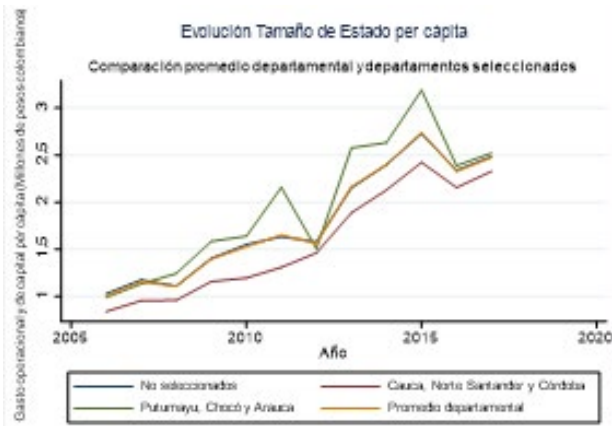

Fuente: Elaboración Propia a partir del DNP. Los departamentos seleccionados han sido elegidos pues presentan hoy en día altas tasas de problemáticas relacionadas al conflicto armado.

\section{Figura 7}

Evolución Cobertura Educación

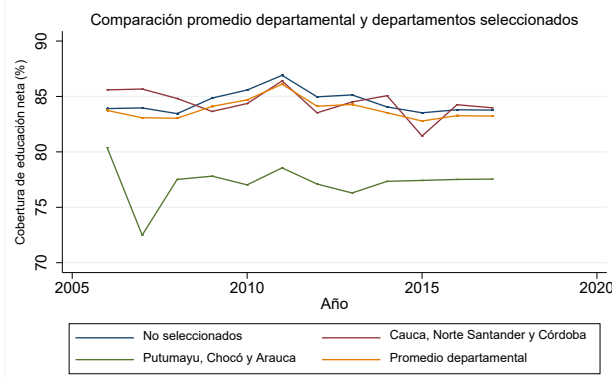

Fuente: Elaboración Propia a partir del Ministerio de Educación. Los departamentos seleccionados han sido elegidos pues presentan hoy en día altas tasas de problemáticas relacionadas al conflicto armado. 
Por tanto, los datos sugieren que no sólo hay diferencias entre el grupo seleccionado y el no seleccionado. De hecho, es posible ver tendencias y variaciones relevantes a lo largo del período estudiado según la intensidad de estos factores. Sin embargo, no se ha discutido aún la hipotética relación negativa entre el crecimiento económico y estos factores de riesgo. Para esto, vemos un análisis mediante el Coeficiente de Correlación de Pearson. El estadístico toma valores positivos o negativos entre $-1 \mathrm{y}+1$, y se calcula con .

Presentamos los valores calculados en la Tabla 3 para toda la muestra y para la Tabla 4 que se replica sólo la última fila, pero restringiendo a los datos de Riesgo Medio y Riesgo Alto. El propósito de este ejercicio, es identificar si la correlación es más intensa en estos grupos. Al analizar la correlación de los factores de riesgo con el crecimiento del PIB, vemos que la relación del crecimiento departamental con la intensidad de economías ilegales es negativa en general, y mayormente en el grupo estudiado. Por otro lado, vemos que mientras la tasa de secuestros tiene relación negativa para homicidios su relación es positiva. Esto puede deberse a que los homicidios no sólo vengan dados por el conflicto armado, es decir, un problema de "reduccionismo metodológico" estudiado previamente. La relación negativa del gasto público con el crecimiento podría explicarse por un esfuerzo contracíclico fiscal ${ }^{89}$. Lo más interesante en nuestra opinión, es que la relación entre el crecimiento económico es positiva para los diferentes tipos de coberturas de servicios públicos estudiados. Sostenemos que estas últimas variables miden de mejor manera la presencia y fortaleza del Estado, pues mayor gasto no implica por sí solo mayor densidad de este, sino su distribución en bienes y servicios públicos básicos. Por otro lado, el gasto público es bastante similar entre los departamentos como se evidenció en la Tabla 1, y no se puede rechazar que entre grupos exista diferencia significativa para el gasto.

89 Contracíclico corresponde a que el Estado decide aportar más gasto público en períodos donde el crecimiento es menor y menos cuando el crecimiento es mayor. Lo que podría explicar una relación negativa. 
Por último, las relaciones son levemente más intensas al focalizarnos en los grupos de riesgo (Tabla 4). En particular, se puede sostener que en base a los datos habría una potencial relación negativa entre Crecimiento PIB y Secuestros, Gasto Público per cápita, menor nivel de acueductos, electrificación, educación. Esto parcialmente va en línea de la hipótesis del conflicto y fortaleza del Estado como potenciales explicaciones del crecimiento económico.

Tabla 3

Análisis de correlaciones para toda la muestra y todas las variables estudiadas.

Años 2006-2016

\begin{tabular}{|c|c|c|c|c|c|c|c|c|}
\hline & $\begin{array}{c}\text { Tasa } \\
\text { Secues- } \\
\text { tros }\end{array}$ & $\begin{array}{c}\text { Tasa } \\
\text { Homici- } \\
\text { dios }\end{array}$ & $\begin{array}{l}\text { Hecta- } \\
\text { reas } \\
\text { Cocaína } \\
\text { (Eco- } \\
\text { nomías } \\
\text { ilegales) }\end{array}$ & $\begin{array}{l}\text { Gasto } \\
\text { públi- } \\
\text { co per } \\
\text { cápita }\end{array}$ & $\begin{array}{l}\text { Cober- } \\
\text { tura } \\
\text { acue- } \\
\text { ductos }\end{array}$ & $\begin{array}{c}\text { Co- } \\
\text { bertu- } \\
\text { ra } \\
\text { Elec- } \\
\text { trica }\end{array}$ & $\begin{array}{l}\text { Co- } \\
\text { ber- } \\
\text { tura } \\
\text { edu- } \\
\text { ca- } \\
\text { ción }\end{array}$ & $\begin{array}{l}\text { Creci- } \\
\text { mien- } \\
\text { to PIB }\end{array}$ \\
\hline $\begin{array}{l}\text { Tasa Se- } \\
\text { cuestros }\end{array}$ & 1 & & & & & & & \\
\hline $\begin{array}{l}\text { Tasa Homi- } \\
\text { cidios }\end{array}$ & $0,4339 * *$ & 1 & & & & & & \\
\hline $\begin{array}{l}\text { Hectareas } \\
\text { Cocaína }\end{array}$ & 0,0418 & $0,1810^{* *}$ & 1 & & & & & \\
\hline $\begin{array}{l}\text { Gasto } \\
\text { público per } \\
\text { cápita }\end{array}$ & 0,517 & $-0,2077 * *$ & $-0,0261$ & 1 & & & & \\
\hline $\begin{array}{l}\text { Cobertura } \\
\text { acueductos }\end{array}$ & $-0,0995^{*}$ & 0,0744 & 0,1296 & 0,0272 & 1 & & & \\
\hline $\begin{array}{l}\text { Cobertura } \\
\text { electrifica- } \\
\text { ción }\end{array}$ & $-0,0401$ & 0,0007 & $-0,1041$ & $-0,0670$ & $0,2698 * *$ & 1 & & \\
\hline $\begin{array}{l}\text { Cobertura } \\
\text { educación }\end{array}$ & $-0,0547$ & $-0,0540$ & $-0,0799$ & $0,1203^{* *}$ & 0,0662 & 0,0240 & 1 & \\
\hline $\begin{array}{l}\text { Crecimien- } \\
\text { to PIB }\end{array}$ & $-0,0239$ & 0,0496 & $-0,0282$ & $-0,3084$ & 0,0507 & 0,1276 & 0,0374 & 1 \\
\hline
\end{tabular}

Nota: Datos de DANE, DNP, Observatorio de Drogas. Toda la muestra. Los datos corresponden a los períodos 2006-2016 salvo para acueductos que parten el 2008 y electrificación el 2011. 
Tabla 4

Análisis de correlación crecimiento PIB y otras variables sólo para grupos de riesgo.

\begin{tabular}{|l|l|l|l|l|l|l|l|}
\hline & $\begin{array}{l}\text { Tasa } \\
\text { Secues- } \\
\text { tros }\end{array}$ & $\begin{array}{l}\text { Tasa Ho- } \\
\text { micidios }\end{array}$ & $\begin{array}{l}\text { Hecta- } \\
\text { reas } \\
\text { Cocaí- } \\
\text { na }\end{array}$ & $\begin{array}{l}\text { Gasto } \\
\text { públi- } \\
\text { co per } \\
\text { cápita }\end{array}$ & $\begin{array}{l}\text { Cober- } \\
\text { tura } \\
\text { acue- } \\
\text { ductos }\end{array}$ & $\begin{array}{l}\text { Cober- } \\
\text { tura } \\
\text { Electri- } \\
\text { ficiación }\end{array}$ & $\begin{array}{l}\text { Cober- } \\
\text { tura } \\
\text { educa- } \\
\text { ción }\end{array}$ \\
\hline $\begin{array}{l}\text { Crecimiento } \\
\text { PIB }\end{array}$ & $-0,1572$ & 0,0554 & $-0,0618$ & $-0,4138$ & 0,1719 & 0,2577 & 0,1608 \\
\hline
\end{tabular}

Nota: Datos de DANE, DNP, Observatorio de Drogas. Muestra restringida a grupos de Riesgo 1 y 2. Los datos corresponden a los períodos 2006-2016 salvo para acueductos que parten el 2008 y electrificación que parten el 2011.

En base a los tres análisis empíricos anteriores podemos concluir que, en primer lugar, es posible identificar grupos objetivamente más expuestos al conflicto. En segundo lugar, los departamentos más expuestos al conflicto a lo largo del tiempo muestran en general factores de riesgo más intensos que el promedio (salvo electrificación), y tienen menores tasas de crecimiento del PIB departamental entre 2006-2016. En tercer lugar, existen una potencial e interesante relación negativa entre parte de la intensidad del conflicto (medida como secuestros), fortaleza y densidad del Estado medida por cobertura de educación, acueductos y electrificación entre 2006-2016. Cabe destacar que los análisis realizados no pretenden explicar causalidad, pues ello escapa del objeto de estudio, que como se señaló, busca sugerir una posible relación negativa entre crecimiento económico y los factores de riesgo.

\section{Conclusiones}

Esta investigación aspiraba a demostrar que la desmovilización de los más importantes actores armados ilegales del conflicto armado, AUC, y FARC-EP, abre una nueva etapa histórica de éste, caracterizado por nuevas formas de violencia, protagonizado por una gran variedad de entidades armadas, residuales, disidencias, rearmados, narcotraficantes, bandas, estructuras armadas de carácter urbano y rural, despolitizadas y criminalizadas. Se evidencia que las organizaciones de mayor tamaño que operan con violencia entre 2006-2016 provienen de viejos actores insurgentes o contrainsurgentes del conflicto armado que han dejado atrás motivaciones de tipo político o ideológico (aunque fuesen 
parciales, aparentes o falsas), para constituirse en organizaciones criminales transfronterizas. Aprovechan a su favor los vacíos institucionales y los factores de riesgo departamentales, los atrasos e incumplimientos de los acuerdos de paz, el incremento de economías ilegales como el narcotráfico, la minería y el contrabando, produciendo una transformación dinámica de la violencia y del conflicto interno.

El trabajo adelanta conclusiones para demostrar empíricamente el impacto negativo que sobre el crecimiento económico tiene el accionar de las organizaciones criminales en 6 departamentos de Colombia considerados de mayor conflictividad, violencia, y peso específico de los "factores de riesgo" para el período de posconflicto tras los acuerdos de paz. Por otro lado, se evidencia que el conflicto se ha desplazado geográficamente en sus vórtices de violencia a departamentos del Pacífico, Norte de Santander y Putumayo. La relación entre crecimiento económico y violencia había sido medida o considerada anteriormente científicamente para el período del Conflicto armado es decir hasta el año 2006. Es evidente que se requieren nuevos parámetros en esa importante relación para este tiempo histórico, (para algunos posconflicto), que ayuden a encauzar, potenciar y mejorar las políticas públicas, la ocupación territorial, todos ellos factores importantes para conseguir logros efectivos y permanentes para desmovilizar la violencia criminal en todas sus formas.

\section{Bibliografía}

\section{FUENTES PRIMARIAS}

Departamento Nacional de Estadísticas del Gobierno de Colombia (DANE). Accedido el 11 de mayo de 2020 en https://www.datos.gov.co/.

Revista Cambio, Edición N 676, 12 de junio del año 2006.

Observatorio de Drogas de Colombia. Accedido el 11 de mayo del 2020 en http://www.odc.gov.co/.

Unidad de Planeación Minero Energética (UPME). Accedido el 11 de mayo del 2020 en https://www1.upme.gov.co/Paginas/default. aspx . 


\section{Prensa}

El Colombiano, Cartel de Sinaloa estaría financiando bandas criminales en Colombia. https://www.elcolombiano.com/colombia/cartel-de-sinaloa-estaria-financiando-bandas-criminales-en-colombia-MI8039691.

El Tiempo, 'La minería criminal va a generar más violencia': Luis Jorge Garay, El Tiempo, 11 de mayo de 2013. https://www.eltiempo. com/archivo/documento/CMS-12793568.

El Espectador, "Radiografía de las disidencias de las Farc”. https:// www.elespectador.com/noticias/judicial/radiografia-de-las-disidencias-de-las-farc/.

El País, Contrabando de gasolina - Venezuela, crimen sin frontera, https://www.elpais.com.co/especiales/venezuela-crimen-sin-frontera/ (accedido 30 de septiembre de 2020).

\section{FuENTES SECUNDARIAS}

Acemoglu, Daron, James A. Robinson, y Rafael J. Santos. "The monopoly of violence: Evidence from Colombia". Journal of the European Economic Association 11 (2013): 5-44.

Ávila, Ariel, y León Valencia. "Los retos del posconflicto: Justicia, seguridad y mercados ilegales”. Bogotá: Ediciones B, 2016.

Borda, Fals, Germán Guzmán Orlando, y Eduardo Umaña. "La violencia en Colombia". Bogotá: Tercer Mundo, 1962.

Cepeda, Iván, y Jorge Rojas. A las puertas del Ubérrimo. DEBATE, 2000.

Del Arenal, Celestino, Robert J. Art, y Robert Jervis. Introducción a las relaciones internacionales. Tecnos, 1984.

Diaz, María Ruiz, John Galeano Raquejo, y Edwin Oswaldo Gil Mateus. "Posconflicto colombiano y sus efectos económicos". Revista CIFE: Lecturas de Economía Social Vol. 17 No. 27 (2015): 2.

Echandía, Camilo. "Narcotráfico: Génesis de los paramilitares y herencia de bandas criminales". Informes FIP 19 (2013): 5-32.

186 Gallego, Carlos Medina, y Mireya Tellez Ardila. La violencia parainstitucional, paramilitar y parapolicial en Colombia. Rodríguez Quito Editores, 1994. 
Gambetta, Diego. La mafia siciliana: el negocio de la protección privada. Fondo de cultura económica, 2007.

García Pérez, Patricio. "Organizaciones armadas post Autodefensas Unidas de Colombia: Del pasado contrainsurgente al presente de criminalidad transnacional. 2006-2016". Izquierdas No. 49 (2020): 141-158.

García Ruiz, María Andrea, Ángela María Silva Aparicio y Marcela Julieth Magallanes Montoya, "Políticas para combatir a los grupos armados posdesmovilización en los gobiernos de Álvaro Uribe Vélez y Juan Manuel Santos", Análisis político Vol. 31 No. 92 (2018): 159-179.

Gibson, Edward. "Subnational Authoritarianism: territorial strategies of political control in democratic regimes". En Annual Meeting of the American Political Science Association, Vol. 2, 2004.

González, Camilo. “¿Hacia la dejación de las armas y el sometimiento del Clan del Golfo?”, Informe XIII sobre narcoparamilitares y grupos armados en el posacuerdo (Bogotá: Unidad de Investigación, INDEPAZ, octubre de 2017).

Kaldor, Mary. New and old wars: Organised violence in a global era. John Wiley \& Sons, 2013.

Keohane, Robert Owen, y Joseph S. Nye. Transnational relations and world politics. Cambridge, Mass.: Harvard University Press, 1971. Krauthausen, Ciro. "Poder y Mercado. El narcotráfico colombiano y la mafia italiana”. Nueva Sociedad No. 130 (1994): 112-125.

Fundación Paz y Reconciliación, La compleja estructura detrás del 'clan delGolfo',16 dejulio de 2018. https://pares.com.co/2018/07/16/ la-compleja-estructura-detras-del-clan-del-golfo/.

Linares Hamann, Jorge Enrique. "Redes criminales transnacionales: principal amenaza para la seguridad internacional en la posguerra fría”. Revista Criminalidad Vol. 50 No. 1 (2008): 371-384.

Medina, C. Mafia, narcotráfico y bandas criminales en Colombia: elementos para un estudio comparado con el caso de México. Bogotá, Colombia: Universidad Nacional de Colombia, 2012.

Ministerio de Relaciones Exteriores. "Intervención de la Canciller María Ángela Holguín en el segmento de alto nivel del 60o Período de Sesiones de la Comisión de Estupefacientes de las Naciones Unidas". Cancillería, 13 de marzo de 2017. https://www.cancille- 
ria.gov.co/newsroom/news/intervencion-canciller-maria-angela-holguin-segmento-alto-nivel-60o-periodo-sesiones.

Murillo, Juan Pablo. "El índice de densidad del Estado como una categoría para el análisis de la mortalidad infantil en el Perú: Un análisis exploratorio”. En Anales de la Facultad de Medicina, 78:326-332. UNMSM. Facultad de Medicina, 2017.

Nye Jr, Joseph S. Soft power: The means to success in world politics. Public affairs, 2004.

Palacios, Marco. "Criminal Businessmen, Commodity Frontiers and the Colombian State". Journal of Applied Business and Economics Vol. 21 No. 6 (2019).

Para citar este artículo: García Pérez, Patricio y García Sanhueza, Julián Andrés "Consideraciones acerca de los actores criminales de Colombia, como mutaciones del conflicto interno, desde la perspectiva económica y de la historia de las relaciones internacionales (2006-2018)", Historia Caribe Vol. XVI No. 39 (Julio-Diciembre 2021):153-188 DOI: https:/ / doi.org/10.15648/hc.39.2021.2963 